\title{
Editorial
}

\section{When medicines fail: recommendations for curbing antibiotic resistance}

\author{
Rachel Nugent ${ }^{1}$ and Iruka N Okeke ${ }^{2}$ \\ ${ }^{1}$ Center for Global Development, 1800 Massachusetts Avenue NW, Washington DC 20036 \\ ${ }^{2}$ Department of Biology, Haverford College, Haverford, PA 19041, USA
}

Key words: antimicrobial resistance, antibiotic resistance, drug resistance, surveillance, drug distribution, antimicrobial development

J Infect Dev Ctries 2010; 4(6):355-356.

(Received 17 May 2010 - Accepted 24 May 2010)

Copyright $\odot 2010$ Nugent and Okeke. This is an open-access article distributed under the Creative Commons Attribution License, which permits unrestricted use, distribution, and reproduction in any medium, provided the original work is properly cited.

Despite tireless efforts to increase access to drugs in developing countries, we are losing our ability to cure common diseases because of the work of an invisible adversary: the drug resistant bug. Drug resistance is on the rise worldwide - not only because of the natural, evolutionary process that occurs as microbes adapt in the presence of drug therapy, but also because humans are hastening resistance, including through inappropriate use of medicines.

Without a concerted global effort to ensure both broad access to drugs and lasting effectiveness of treatment, drug resistance will continue to cost lives, increase the cost of curing patients, and render future generations vulnerable to diseases as they rely on a shrinking collection of medicines that work.

Sixty-five years ago, Sir Alexander Fleming was awarded the Nobel Prize in Physiology or Medicine. He said, "The time may come when penicillin can be bought by anyone in the shops. Then there is the danger that the ignorant man may easily underdose himself and by exposing his microbes to non-lethal quantities of the drug make them resistant" [1]. Fleming's fears have come true, and today, we can now foresee a post-penicillin world.

Although the full extent of the problem remains under-reported, resistance is clearly on the rise, resulting in costly economic and health consequences. Drug resistance has reversed or slowed gains against childhood diarrhoea and pneumonia, dramatically increased the costs of fighting tuberculosis and malaria, and now threatens the effort to effectively treat people living with HIV/AIDS. In some cases, resistance is occurring almost as quickly as drugs are appearing on the market; and if the first treatment doesn't work, alternative ones are almost always more costly, harder to use, have a greater number of adverse effects, and require greater medical oversight.

Drug resistance costs lives, and the consequences can be most profound for children, who are especially susceptible to infectious diseases. Together, pneumonia, diarrhoea, and malaria cause 41 percent of the estimated 8.8 million deaths of under-fiveyear-olds in 2008 [2]. Many cases of these illnesses are from strains resistant to common drugs. In this issue, Mengo, Muigai, Revathi and Kariuki report that $70 \%$ of Salmonella Typhi isolated in Nairobi, Kenya, between 2004 and 2006 are multi-drug resistant.

Wealthier countries also suffer from resistance problems. "Superbugs" such as methicillin-resistant Staphylococcus aureas (MRSA) increased from roughly $2 \%$ to more than $60 \%$ of staph infections in many US hospitals between 1974 and 2004, resulting in tens of thousands of deaths $[3,4]$. Equally worrying is the parallel emergence of extended-spectrum betalactamase (ESBL)-producing Gram negative bacteria in European and North American hospitals [5]. Both MRSA and ESBL-producers are now reported globally, with Khan and co-workers and Marchiaro et al. reporting ESBL-producers from Pakistan and Argentina respectively in this issue of JIDC.

In addition to health consequences, resistance to drugs has a startling impact on the cost of curing patients. It costs as much to cure one patient of extensively drug-resistant TB as it does to cure 200 patients of susceptible TB [6]. Mengo et al.'s 
recommendation (in this issue), that the use of cheap first-line drugs to treat typhoid fever in Nairobi be discontinued will similarly have enormous cost implications since the alternatives - currently fluoroquinolones, to which resistance has begun to emerge-are three to ten times more expensive. Where resources are finite or inadequate, for every person put on second-line treatment, far fewer people can be given access to life-saving or life-extending care.

Responding to the growing threat of drug resistance and growing need for a more extensive and systematic global response, the Center for Global Development convened an expert Drug Resistance Working Group in late 2007 to identify practical ways to combat global drug resistance, particularly for high-burden diseases affecting developing countries. In a just-completed report <www.whenmedicinesfail.org>, the Working Group urges pharmaceutical companies, governments, donors, and global health institutions to lead on this increasingly urgent global health threat, and offers four key recommendations:

1.Improve surveillance by collecting and sharing resistance information across networks of laboratories

2.Secure the drug supply chain to ensure quality product and practice

3. Strengthen the reach and capabilities of National Drug Regulatory Authorities

4. Catalyze research and innovation to speed the development of resistance-fighting technologies

The Working Group's recommendations target four critical areas: surveillance and laboratory capacity; the integrity of the drug supply chain; regulatory capacity; and the technology pipeline. Each has merit individually but it will take a coordinated, balanced approach to tackle drug resistance effectively on a global scale (Figure 1), supported by strong global leadership.

We can no longer afford to be indifferent to the spread of drug-resistant diseases. We must show collective leadership if we are to meet this challenge. For the sake of all people who seek effective health care, now and in the future, drug resistance must be addressed urgently and aggressively as a global health priority.
Figure 1. Tackling drug resistance will require a coordinated and balanced approach

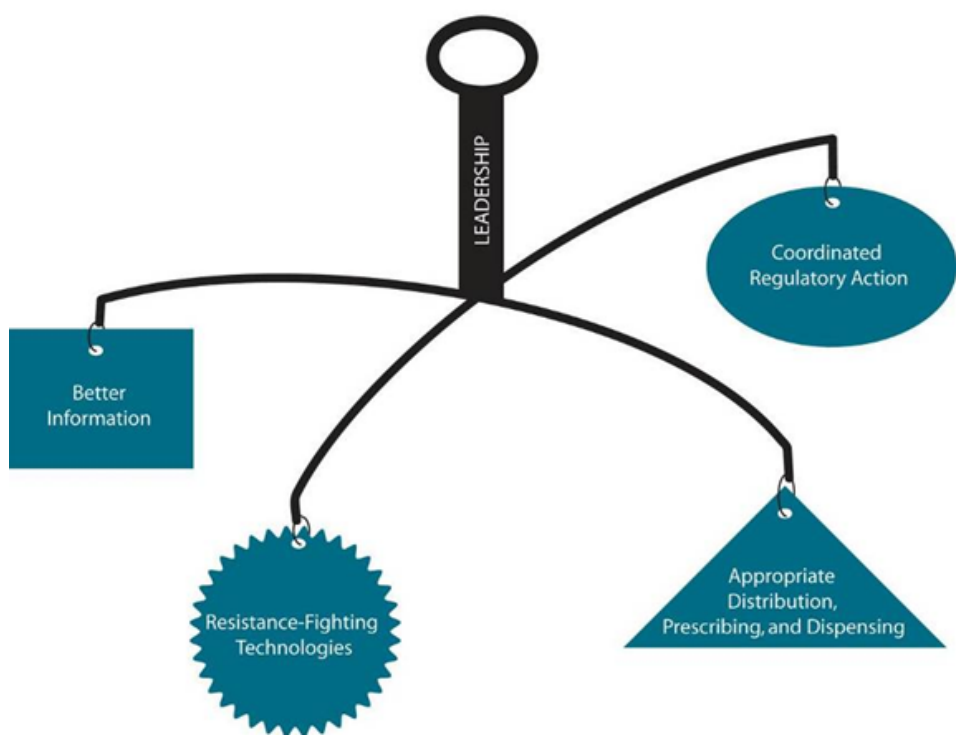

\section{References}

1. Fleming A (1945) Penicillin. Nobel Lectures. Stockholm.

2. Black RE, Cousens S, Johnson HL, Lawn JE, Rudan I, Bassani DG, Jha P, Campbell H, Walker CF, Cibulskis R, Eisele T, Liu L, Mathers $\mathrm{C}$; for the Child Health Epidemiology Reference Group of WHO and UNICEF. (2010) Global, regional, and national causes of child mortality in 2008: a systematic analysis. Lancet 375:19691987.

3. Klevens RM, Edwards JR, Tenover FC, McDonald LC, Horan T, Gaynes, R. (2006) Changes in the epidemiology of methicillin-resistant Staphylococcus aureus in intensive care units in US hospitals, 1992-2003. Clin Infect Dis 42: 389391.

4. Boucher HW, Corey GR (2008) Epidemiology of methicillin-resistant Staphylococcus aureus. Clin Infect Dis 46: S344-349.

5. Pitout JD, Laupland KB (2008) Extended-spectrum betalactamase-producing Enterobacteriaceae: an emerging public-health concern. Lancet Infect Dis 8: 159-166.

6. Floyd K, Pantoja A (2008) Financial resources required for tuberculosis control to achieve global targets set for 2015 . Bull World Health Organ 86: 568-576.

\section{Corresponding author}

Rachel Nugent

Center for Global Development

1800 Massachusetts Avenue NW

Washington DC 20036 USA

Email: rnugent@cgdev.org

Conflict of interests: No conflict of interests is declared. 